\title{
An Evaluation of the Localization Quality of the Arabic Versions of Learning Management Systems
}

\author{
Abdulfattah Omar \\ Department of English \\ College of Science and Humanities \\ Prince Sattam Bin Abdulaziz University, Saudi Arabia \\ Department of English, Faculty of Arts, Port Said University, Egypt
}

\begin{abstract}
The recent years have witnessed the development of numerous Learning Management Systems (LMSs) to address the increasing needs of individuals and institutions all over the world. For accessibility and commercial purposes, many of these LMSs are released in different languages using what is known as localization systems. In this regard, there has been a parallel between the development of LMSs on one hand and the localization systems on the other. One main aspect in the recent evaluation systems and studies of LMSs is localization quality. Despite the prolific literature on localization quality, very little has been done on Arabic localization. As thus, this study is concerned with the evaluation of the localization quality of the Arabic version of LMSs. In order to explore users' perceptions towards the Arabic versions of the LMSs, an online questionnaire was conducted. Participants were asked about their familiarity with LMSs and whether they used the Arabic versions of these systems. They were also asked about their experiences with the Arabic localization of these systems and whether they faced any problems in dealing with the Arabic version. The findings indicate that translation inconsistencies are the main problems with the Arabic versions of different LMSs including Blackboard Learn, Microsoft Teams, and Zoom. These problems have negative impacts on the effectiveness and reliability of these systems in schools, universities, and training institutions. For the proper implementation of LMSs both localization and translation should go hand-in-hand. Localization developers and LMSs designers need to consider the linguistic the peculiar linguistic features of Arabic. The findings of the study have implications to translation programs in Arab universities and training institutions. Program designers should integrate translation technologies and localization systems into translation studies. They need to consider the changes within the translation industry. The study was limited to the study of translation quality in the Arabic versions of the localized LMSs. The localization quality of other software programs, games, websites, and applications needs to be explored. Finally, it is recommended to develop a quality matrix that encompasses all the dimensions and peculiarities of Arabic localization.
\end{abstract}

Keywords-Ambiguity; Arabic; language inconsistencies; Learning Management Systems (LMSs); localization quality

\section{INTRODUCTION}

The recent years have witnessed the development of numerous learning technologies including what have come to be known as the Learning Management Systems (LMSs) to address the changing needs of individuals and institutions all over the world. These newly developed learning systems have revolutionized and changed the way we look at knowledge and skill acquisition [1-4]. LMSs are designed to help organizations manage training events, self-paced courses, and blended learning programs. Organizations and academic institutions have realized that these new learning systems are good alternatives for the traditional rigorous and expensive teaching patterns. This may explain the boom in the LMS market over the recent years.

The unprecedented increase in the development of LMSs can be attributed to different reasons including the development of global economies and multinational institutions as well as the changing patterns within teaching and learning. Furthermore, the emergence of the pandemic COVID-19 has posed strong pressures on the developers of elearning technologies to develop reliable and effective LMSs that can help students and institutions cope up with this dilemma that has changed our lives in drastic ways and represents unique challenges to all institutions around the world [5-8].

According to Verma [5], Covid-19 has brought out the importance of effective and reliable LMSs that can be usefully used to rescue the prevailing dilemmas in continuing education. In the same saying, Holland [9] asserts that elearning technologies and LMSs are playing a significant role in current times. Many researchers and educators stress that LMSs have been playing an influential role in supporting the education systems and training institutions during the pandemic COVID-19 [6]. According to Raza, et al. [6], learning technologies and LMSs have proved effective in building effective learning environments during this challenging transition in our contemporary history.

Apart from COVID-19, it is argued that the development of LMSs has changed the nature of learning and training [10-13]. According to Stone [14].

Traditionally, Learning Management Systems (LMS) have been designed to deliver, manage, track, and assess learning activities in a formal learning environment. With new forms of communication and content sharing as well as social networking services (both open and closed), a new generation of systems is emerging to facilitate teaching and learning. These new systems are brought into educational institutions to support new teaching and learning environments and emerging social trends as well as to impact the traditional administration and business models. 
The increasingly competitive global marketplace for jobs and education has thus posed different challenges for educational institutions to integrate e-learning technologies and LMSs into their systems. In this regard, the education systems in different Arab countries, Alshahrani and Ally [10] argue, have started to use innovative pedagogies best practices in teaching and learning in all education stages to address the needs of learners and to provide maximum flexibility in learning.

In the face of the digital transformation processes and the pandemic COVID-19, schools, universities, and training institutions have started to integrate learning technologies and LMSs into their teaching and learning practices [8, 15-17]. The selection of an appropriate LMS is usually based on different factors including cost, nature of the courses, age and level of the students, and the availability of an Arabic version of the selected LMS. The rationale is that schools, universities, and training institutions tend to ensure that LMSs are delivered in the same way to all users globally, regardless of linguistic differences, many users still have difficulties dealing with the systems in various target languages. In other words, localization, defined as the process of adapting a software product, website, or application to the linguistic, cultural, and technical requirements, needs, and outlook of a target market [18-23], is one main criterion in the selection of appropriate LMSs.

Over the recent years, there is a close relationship between e-learning systems and technologies on one hand and localization on the other hand. Gauld [24] asserts that localization tools have made the process relatively straightforward for both the educators and their language partners. This has resulted in an exponential growth in the eLearning industry that is projected to be worth $\$ 331$ billion by 2025.

The selection of appropriate LMSs is not always straightforward. Education and training institutions, therefore, have to ensure the localization quality of the Arabic versions of the LMSs. Localization quality is one of the main requirements for the localization process of an LMS. Reliable localization should be based on unambiguous and understandable language, the appropriate language level, standardization of terminology, provision of sufficient context to the translators, and validation of the target text $[19,22,25]$.

In order to support individuals and institutions select proper LMSs, reliable and comprehensive evaluation and assessments of LMSs and the way they work should be generated. In light of this argument, this study seeks to provide an evaluation of the Arabic versions of LMSs. The purpose is to help individuals and institutions with the selection of appropriate LMSs on one hand, and to provide working and reliable solutions and strategies to localization developers to improve their effectiveness and performance.

The rest of this article is organized as follows. Section 2 is Literature Review. It provides a brief survey of localization evaluation and assessment systems. Section 3 is Methodology. It describes the methods and procedures of the study. Section 4 is Analysis and Discussions. It provides both qualitative and qualitative analyses of the data and information gathered through the survey. Section 5 is the Conclusion. It summarizes the main findings, recommendations, and implications of the study.

\section{LITERATURE REVIEW}

Numerous studies have been recently developed to evaluate and assess the accuracy and reliability of localization systems in different languages, including Chinese, Hindu, Russian, and Spanish. This can be attributed to the growing popularity of localization systems and services which have been parallel to the unprecedented development in web applications and software programs. Zhang [26] comments that currently localization is an important requirement in many international corporations. It is utilized in many kinds of services, such as translation, QA, DTP, testing, and project management. He adds that within the global changes we witness today, localization organizations are providing localization solutions for multiple languages. In this regard, Zhang suggests that it is important to develop evaluation systems to manage localization projects and ensure effective quality management. Likewise, Hassan [27] explains that evaluation systems help both users and localization project managers be confident of the quality delivered. It is universally accepted that localization quality is one of the key success factors of brands, applications, and software programs [28-31].

Given the importance of developing evaluation systems and criteria for localization quality assurance, different approaches have been generated. These approaches have been primarily concerned with assessing the localization quality in terms of consistency and precision of localization systems by contrasting the source and target segments [19, 32-35]. Localization quality, Lobanov [36] defines, is a state of the translated text, such that the language is correct, accurately reflects the idea of the original, takes into account cultural specifics, and is easy for the target audience to read and use. In other words, localization quality is achieved when the translated text reveals the idea of the original accurately in the target language.

The evaluation of localization quality is usually based on three criteria: language translation or linguistic properties, the transition of the product, and the outcome of the product. Allen, et al. [34] asserts that the quality of the translation is one of the main criteria of the localization quality. The quality of the translation entails also defining the target audience. That is, the quality of translation requires that the language is accessible to the target audience. Localization developers should consider the cultural and religious sensitivity of the target audience [18, 20]. Failing to consider such sensitive issues can have negative impacts on the accessibility, marketing, and value of software products and applications [37-39].

Concerning the localization of LMSs, Núñez [40] argues that LMSs should have multilingual support. That is, they should come in different languages because not all students, trainees, and instructors will be able to understand how to navigate the user interface, if it is not translated in their native languages. She asserts that LMSs that support multiple languages for their users, become highly engaging systems as they help optimize user experience by localizing the process 
and putting an end to geographical boundaries. In this sense, localization quality is one of the key elements of successful and reliable LMSs.

Gauld [24] argues that the localization processes of LMSs should consider the translation of the written content, graphics, navigation buttons, images, audio and video materials, and data formats. Fadil and Khaldi [41] add that the translation of the contents should be converted into accessible language so that LMSs can make a real impact on learning environments.

Despite the existence of prolific literature on localization evaluation and assessment, research on Arabic localization in general and the Arabic localization of LMSs, in particular, is very sparse. This may be attributed in part to the misconceptions that users in the Arab world generally prefer to use the applications and software programs in their original languages $[42,43]$. These misconceptions can be due to the lack of statistics and field studies on linguistic preferences and attitudes towards the use of software applications.

Very few studies, however, have been recently done on evaluating the Arabic localization of some applications, software programs, and games. For instance, Omar and Alqahtani [44] addressed the linguistic challenges in the localization of Enterprise Resource Planning (ERP) systems. The authors reported different linguistic problems related to the use of these systems in the Saudi universities. The authors suggested that all ERP instructions, data, applications, and screens should be made available in a clear and accessible language for the successful implementation of these systems. They finally recommended institutions select the ERP systems that are embedded with multi-language capabilities to address the linguistic needs of all employees and stakeholders. Despite the focus of the study on the language problems and challenges in the Saudi universities and the proper selection of localization systems, it did not provide solutions to Arabic localization problems. Furthermore, the issue of LMSs was not considered within the ERP theoretical framework.

To our knowledge, the first attempt to evaluate the performance of Arabic localizers and the attitudes and perceptions of individuals towards Arabic localization was developed by Al-Mazrooa [42]. In her study of the translation performance in the Arabic versions of some applications including Blackboard Learn and FIFA Video Games, AlMazrooa referred to many problems including language inconsistencies that pose serious challenges for users in the Arab countries. Accordingly, she recommends localization developers consider these problems and challenges so that Arab users can use these applications in the same way native users do in their languages. Despite the contributions of the study to the Arabic localization literature, the study was not focused on LMSs. It was confined to Blackboard Learn in the Saudi universities.

In a recent study, however, Omar, et al. [43] attempted a comprehensive analysis of language problems in LMS. In their analysis of the ambiguity in Arabic localization, they focused on LMSs including Blackboard Learn, Microsoft Teams, and Zoom. This study has addressed the issue of localization quality in LMSs through investigating whether the language content and translated texts are clearly conveyed in Arabic. The authors indicate that localization quality is a key factor for the reliability, and successful and effective use of LMSs which requires that language content be consistently converted into Arabic. They also indicated that most users generally prefer to use software applications in their native languages. They reported that in Arab countries, users still prefer to use software applications and LMSs in Arabic despite the dominance of English as a global language. They concluded that ambiguity and linguistic inconsistencies are two serious problems that have negative impacts on the localization quality of LMSs, and thus have adverse impacts on the effectiveness and reliability of such systems. They finally suggested that localization developers pay attention to the peculiar linguistic features of Arabic and develop effective strategies for terminology management.

One main problem with their study, however, is that the results cannot be appropriately generalized. The number of the participants in the study is very limited compared to the recent reports indicating the number of LMSs users in the Arab world. In light of this limitation, this study seeks to bridge the gap in the literature through evaluating the localization quality of the Arabic versions of the LMSs.

\section{Methods, ProcedurES AND RESUlts}

To explore users' perceptions towards the Arabic versions of the LMSs, an online questionnaire was conducted. The rationale is that questionnaires are appropriate tools for gathering and collecting large amounts of information from a large number of people. The underlying principle was that an online questionnaire is convenient and can be usefully used to bring in a high response, giving also the respondents the flexibility to answer the questions on their own schedule at a pace they choose.

As the study was essentially concerned with the Arabic localization of LMSs, it was appropriate to target only those involved in academic and learning contexts. Participants were asked about their familiarity with LMSs and whether they used the Arabic versions of these systems. They were also asked about their experiences with the Arabic localization of these systems and whether they faced any problems in dealing with the Arabic version.

In total, 7263 participants from 13 Arab countries, including Algeria, Bahrain, Egypt, Jordan, Kuwait, Libya, Morocco, Oman, Palestine, Qatar, Saudi Arabia, Sudan, Tunisia, and the United Arab Emirates, responded to the survey. The participants reflected different age groups, social backgrounds, and nationalities.

In terms of countries, Saudi Arabia and Egypt represent the two biggest participating countries, as shown in Fig. 1. This can be related to the number of internet users, schools, and universities in the two countries. According to reports released by the Egyptian Central Agency for Public Mobilization and Statistics in November 2020, there are about 3.1 million students in the universities and other Higher Education institutions. Concerning Saudi Arabia, the recent years have witnessed the development of many universities. Today, there are 51 universities in Saudi Arabia. Almost all these countries 
have adopted digital transformation initiatives over the last five years to convert traditional classes into smart ones [45].

In terms of age, the majority of the participants belong to the age group 18-45, as shown in Fig. 2. This is not surprising anyway. According to Johnson [46], around two-thirds of online users worldwide are aged between 18 and 45 years. It is assumed that these rates do not represent any problems with the representativeness of the data.

The participants included pre-university and university students, teachers, faculty, and information technology (IT) staff in both public and private institutions, as shown in Fig. 3. The participants represented more than 20 universities including King Abdulaziz University, King Saud University, Prince Sattam Bin Abdulaziz University, Northern Borders University, Mansoura University, Assuit University, Port Said University, Suez Canal University, Bahrain University, the University of Jordan, and the University of Nizwa.

Responding to the use and familiarity of LMSs, around 87 of the participants indicated that they used LMSs in their education and training. This is not surprising, however. Almost all educational institutions in the Arab countries have integrated learning technologies and LMSs into their teaching processes over the last two years. This also explains the reason that the majority (around $78 \%$ of the participants) used LMSs only over the last two years. This also reflects the fact that LMSs were not widely used before the outbreak of the pandemic COVID-19.

Concerning the most common LMSs, the majority of the participants referred to Blackboard Learn, Blink, Moodle, Microsoft Teams, and Zoom, as shown in Fig. 4.

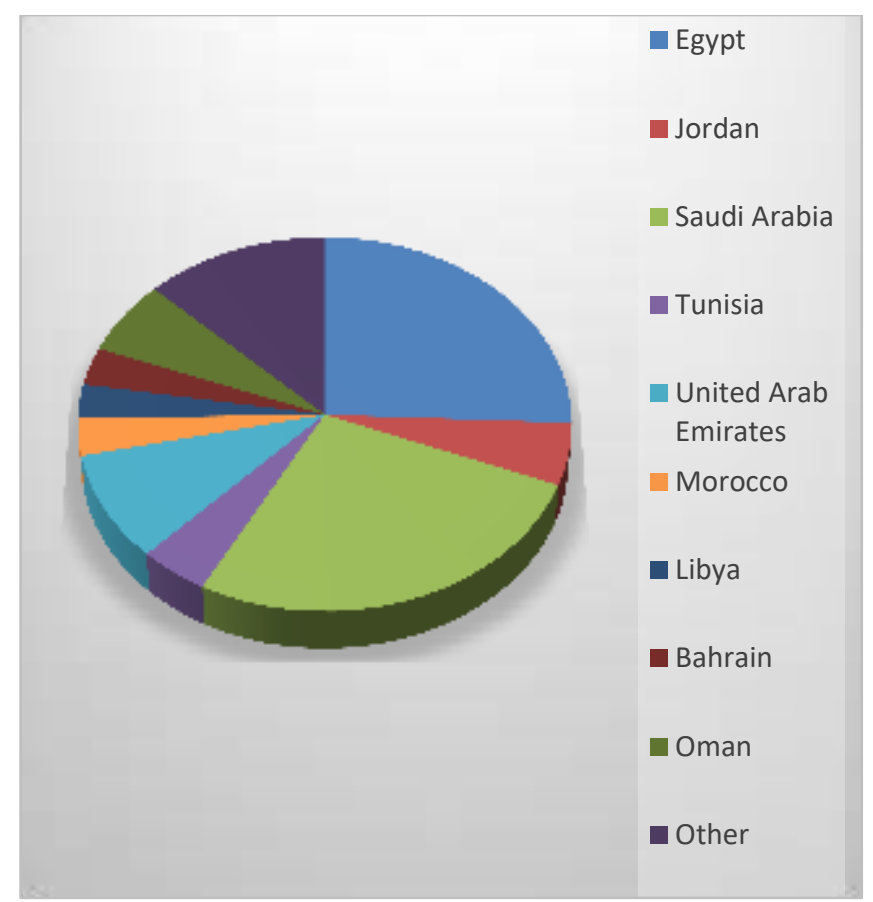

Fig. 1. Participants by Country.

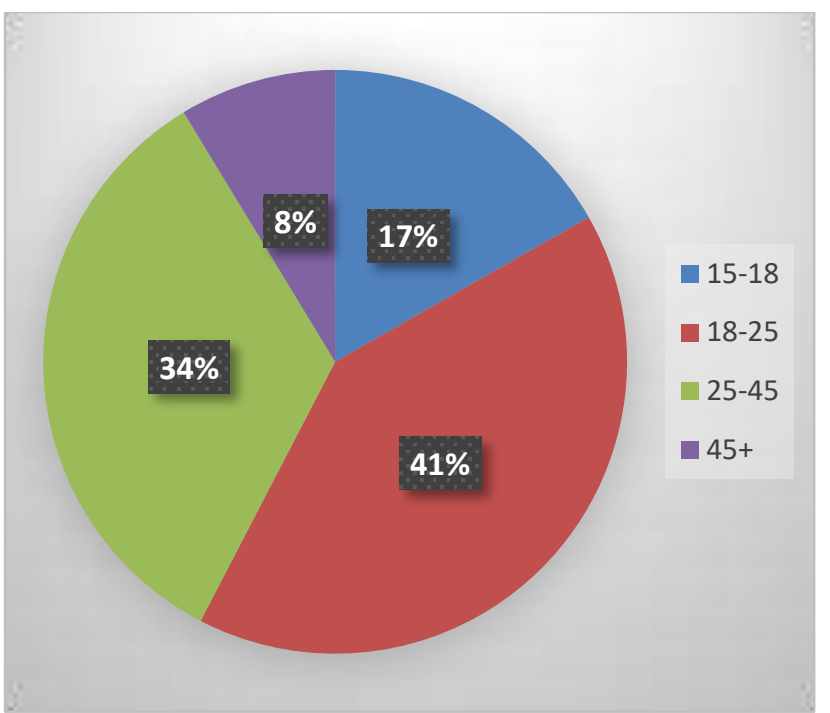

Fig. 2. Participants by Age.

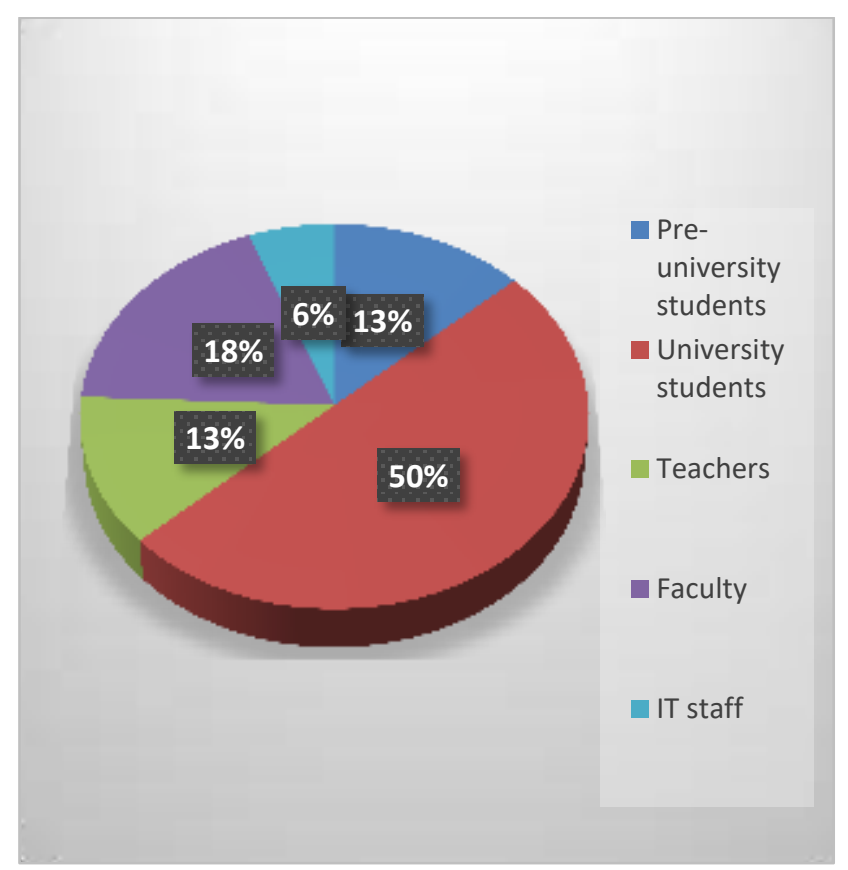

Fig. 3. Participants by Profession.

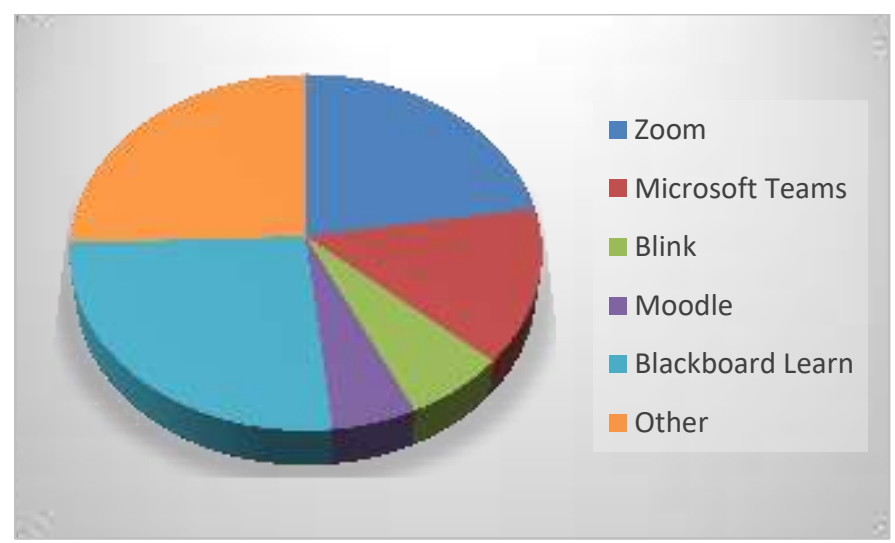

Fig. 4. The Most Commonly used LMSs. 
Some of the participants referred to Facebook and WhatsApp as LMSs. Regardless of the recognition of these applications as LMSs, it was clear that many institutions were not ready to cope up with the changes brought up by COVID19. Instructors and faculty members, therefore, had to use such applications as free and available avenues and channels to communicate with their students [47-49].

73 percent of the participants chose to use the LMS in Arabic with respect to language preferences. However, about $19 \%$ indicated that when they had trouble understanding the material in Arabic, they typically moved to the English or original versions. Finally, around $83 \%$ stressed that they were facing problems with the use of the Arabic versions of localized LMSs. These problems included ambiguous content, unclear instructions, and language inconsistencies.

\section{ANALYSIS AND DISCUSSIONS}

The findings clearly show the widespread of LMSs in the Arab academic institutions as reflected in the participants' familiarity with these systems. The widespread of such systems will definitely have positive impacts on the digital transformation processes and learning processes in the Arab educational institutions. Lack of localization quality, however, is a serious problem that may have adverse impacts on the reliability and effectiveness of such systems.

The major problem with the Arabic versions of the localized LMSs can be described under the heading 'translation inconsistencies'. These inconsistencies definitely have negative impacts on localization quality and reliability [50]. Generally, it is not easy for LMSs users to understand the instructions and terminologies in these systems.

The issue of translation inconsistencies within LMSs can be discussed in the wider context of the challenges of technical translation in Arabic. Technical texts usually contain tough words and expressions which require even tougher translation standards. The translation of technical terms into an accessible language is usually challenging in Arabic [51]. According to Omar, et al. [43], there are thousands of English and Western technical terms that have no direct equivalents in Arabic. It is not easy therefore for translators to convert the terms and instructions in a clear language taking into consideration other factors including space, format, and style. In other words, LMSs usually support different languages where translators are required to be committed to definite templates and designs. Given the fact that not all languages are identical, localization developers, therefore, need to address the linguistic challenges and peculiarities of Arabic, including its morphology, writing system, and dialectal diversity. Indeed, the peculiar linguistic features of Arabic remain among the most serious challenges that have negative impacts on the NPL applications including information retrieval, machine translation, and definitely localization [52-56].

The Arabic localization systems should be aligned with the universal quality standards. These include the quality matrix developed by Lommel, et al. [57]. The matrix is defined into major dimensions including accuracy, design, fluency, internationalization, locale convention, style, terminology, verity, and compatibility. The matrix is graphically represented as shown in Fig. 5.

Finally, the findings of the study indicate clearly that there are serious problems with the translation programs in the Arab universities. Program designers should consider the importance of making students familiar with language technologies and localization systems [58]. Universities and training institutions are also required to consider the changes within the translation industry. Translation should be considered as a product and accordingly, graduates should be prepared and qualified for their careers to stand out in the highly competitive labor markets [59].

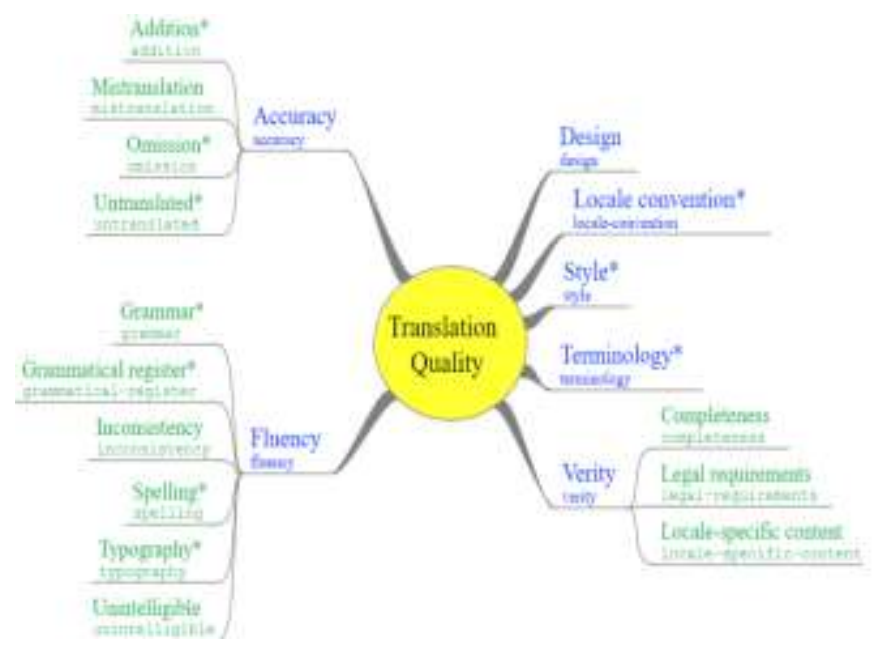

Fig. 5. Quality Matrix Developed by Lommel, et al. [57].

\section{CONCLUSION}

There is general dissatisfaction among users of the Arabic versions of the LMSs about the localization quality. The majority of the participants asserted that the use of the English versions of the LMSs is more convenient and reliable. The Arabic versions of LMSs including Blackboard Learn, Zoom, and Microsoft Teams were blamed for ambiguous instructions and language/translation inconsistencies. These problems have negative impacts on the effectiveness and reliability of these systems in schools, universities, and training institutions.

In order to implement LMSs successfully in schools, universities, and training institutions, both localization and translation should go hand-in-hand. Language content, including words, terms, and phrases, should be consistently converted into accessible Arabic. In this sense, localization developers and LMSs designers need to consider the linguistic variations and diversity of Arabic as well as the different needs of users all over the Arab countries. They need also to consider the peculiar linguistic features of Arabic.

The findings of the study have implications for translation programs in Arab universities and training institutions. Program designers should integrate translation technologies and localization systems into translation studies. They need to consider the changes within the translation industry.

The study was limited to the study of translation quality in the Arabic versions of the localized LMSs. The localization quality of other software programs, games, websites, and 
applications needs to be explored. Finally, it is recommended to develop a quality matrix that encompasses all the dimensions and peculiarities of Arabic localization.

\section{ACKNOWLEDGMENT}

We take this opportunity to thank Prince Sattam Bin Abdulaziz University in Saudi Arabia alongside its Scientific Deanship, for all technical support it has unstintingly provided towards the fulfillment of the current research project.

\section{REFERENCES}

[1] Y. Kats, Learning Management System Technologies and Software Solutions for Online Teaching: Tools and Applications: Tools and Applications. Pennsylvania: Information Science Reference, 2010.

[2] Y. Kats, Learning Management Systems and Instructional Design: Best Practices in Online Education. Hershey, Pennsylvania: IGI Global, 2013.

[3] S. B. Dias, J. A. Diniz, and L. J. Hadjileontiadis, Towards an Intelligent Learning Management System Under Blended Learning: Trends, Profiles and Modeling Perspectives. New York: Springer International Publishing, 2013.

[4] S. Foreman, The LMS Guidebook: Learning Management Systems Demystified American Society for Training \& Development, 2017.

[5] M. C. Verma, New Paradigm in eLearning Technologies Arising Due To Covid-19 Crisis. EPFRA, 2020.

[6] S. A. Raza, W. Qazi, K. A. Khan, and J. Salam, "Social Isolation and Acceptance of the Learning Management System (LMS) in the time of COVID-19 Pandemic: An Expansion of the UTAUT Model," Journal of Educational Computing Research, p. 0735633120960421, 2020.

[7] Z. Alrefaie, M. Hassanien, and A. Al-Hayani, "Monitoring online learning during COVID-19 pandemic; Suggested online learning portfolio (COVID-19 OLP)," MedEdPublish, vol. 9, 2020.

[8] G. Korkmaz and Ç. Toraman, "Are we ready for the post-COVID-19 educational practice? An investigation into what educators think as to online learning," International Journal of Technology in Education and Science (IJTES), vol. 4, no. 4, pp. 293-309, 2020.

[9] B. Holland, Handbook of Research on Library Response to the COVID19 Pandemic. Hershey, Pennsylvania: IGI Global, 2021.

[10] K. Alshahrani and M. Ally, Transforming Education in the Gulf Region: Emerging Learning Technologies and Innovative Pedagogy for the 21st Century. London; New York: Routledge, 2017.

[11] S. S. Binyamin, M. J. Rutter, and S. Smith, "Extending the Technology Acceptance Model to Understand Students' use of Learning Management Systems in Saudi Higher Education," International Journal of Emerging Technologies in Learning, vol. 14, no. 3, 2019.

[12] A. I. Saroia and S. Gao, "Investigating university students' intention to use mobile learning management systems in Sweden," Innovations in Education and Teaching International, vol. 56, no. 5, pp. 569-580, 2019.

[13] Y. Tjong, L. Sugandi, A. Nurshafita, Y. Magdalena, C. Evelyn, and N. S. Yosieto, "User Satisfaction Factors on Learning Management Systems Usage," in 2018 International Conference on Information Management and Technology (ICIMTech), 2018, pp. 11-14: IEEE.

[14] D. E. Stone, "Learning Management Systems in a Changing Environment," in Handbook of Research on Education and Technology in a Changing Society, V. X. Wang, Ed. Hershey, Pennsylvania: IGI Global, 2014, pp. 756-767.

[15] L. Mishra, T. Gupta, and A. Shree, "Online teaching-learning in higher education during lockdown period of COVID-19 pandemic," International Journal of Educational Research Open, vol. 1, p. 100012, 2020.

[16] J. Delcker and D. Ifenthaler, "Teachers' perspective on school development at German vocational schools during the Covid-19 pandemic," Technology, Pedagogy and Education, pp. 1-15, 2020.

[17] C. Carrillo and M. A. Flores, "COVID-19 and teacher education: a literature review of online teaching and learning practices," European Journal of Teacher Education, vol. 43, no. 4, pp. 466-487, 2020.

[18] R. Čermák and Z. Smutny, "A Framework for Cultural Localization of Websites and for Improving Their Commercial Utilization," in Global
Observations of the Influence of Culture on Consumer Buying BehaviorEdition: Advances in Business Strategy and Competitive Advantage, S. Sarma, Ed. Hershey, Pennsylvania: IGI Global, 2018.

[19] M. A. Jimenez-Crespo, Translation and Web Localization. London; New York: Routledge, 2013.

[20] K. Keniston, Software Localization: Notes on Technology and Culture. Cambridge: Massachusetts: The Massachusetts Institute of Technology, 1997.

[21] G. Mao and B. Fidan, Localization Algorithms and Strategies for Wireless Sensor Networks: Monitoring and Surveillance Techniques for Target Tracking: Monitoring and Surveillance Techniques for Target Tracking Information Science Reference, 2009.

[22] K. J. Dunne, Perspectives on Localization. J. Benjamins Publishing Company, 2006.

[23] B. Maylath and K. S. Amant, Translation and Localization: A Guide for Technical and Professional Communicators. London; New York: Routledge, 2019.

[24] N. Gauld. (2018, April 15, 2018) Five Things You Need To Know About eLearning Localization. E-Learning Industry. Available: https://elearningindustry.com/elearning-localization-5-things-needknow.

[25] N. Skoryukina, J. Shemiakina, V. L. Arlazarov, and I. Faradjev, "Document localization algorithms based on feature points and straight lines," in Tenth International Conference on Machine Vision (ICMV 2017), 2018, vol. 10696, p. 106961H: International Society for Optics and Photonics.

[26] K. Zhang, "Translation Quality Management Model for Multilanguage localization in Outsourcing Environment," Translation Directory.

[27] M. Hassan. (2018, March 22, 2018) Translation Quality Assessment: Error Categories and Severity. Vocalink Global. Available: https://vocalinkglobal.com/translation-quality-assessment-errorscategories/.

[28] M. Nogueira Cortimiglia, A. Ghezzi, and F. Renga, "Social applications: Revenue models, delivery channels, and critical success factors-An exploratory study and evidence from the Spanish-speaking market," Journal of theoretical and applied electronic commerce research, vol. 6, no. 2, pp. 108-122, 2011.

[29] V. R. Tummala, C. L. Phillips, and M. Johnson, "Assessing supply chain management success factors: a case study," Supply Chain Management: An International Journal, 2006.

[30] R. Heeks and B. Nicholson, "Software export success factors and strategies in 'follower'nations," Competition \& Change, vol. 8, no. 3, pp. 267-303, 2004.

[31] S. Shin, H. Kim, and W. Kim, "Transnational corporations' localization strategies via retail attributes: Focus on Chinese Market," Journal of Retailing and Consumer Services, vol. 55, p. 102088, 2020.

[32] B. Esselink, A Practical Guide to Localization. John Benjamins Publishing Company, 2000.

[33] M. C. Chao, N. Singh, and Y. N. Chen, "Web site localization in the Chinese market," Journal of Electronic Commerce Research, vol. 13, no. 1, p. 33, 2012.

[34] M. Allen, S. Baydere, E. Gaura, and G. Kucuk, "Evaluation of localization algorithms," in Localization Algorithms and Strategies for Wireless Sensor Networks: Monitoring and Surveillance Techniques for Target TrackingHershey, Pennsylvania: IGI Global, 2009, pp. 348-379.

[35] F. Zafari, A. Gkelias, and K. K. Leung, "A survey of indoor localization systems and technologies," IEEE Communications Surveys \& Tutorials, vol. 21, no. 3, pp. 2568-2599, 2019.

[36] M. Lobanov. (2014, August 21, 2014) Localization quality. A myth or reality? Multilingual. 1-4.

[37] S. Abufardeh and K. Magel, "The impact of global software cultural and linguistic aspects on Global Software Development process (GSD): Issues and Challenges," in 4th International Conference on New Trends in Information Science and Service Science, 2010, pp. 133-138: IEEE.

[38] G. Ger, "Localizing in the global village: Local firms competing in global markets," California Management Review, vol. 41, no. 4, pp. 6483, 1999. 
[39] S. A. Becker, "An exploratory study on web usability and the internationalization of US e-businesses," J. Electron. Commerce Res., vol. 3, no. 4, pp. 265-278, 2002.

[40] M. Núñez. (2019, July 11, 2019) Reasons to Translate Learning Management Systems. SuimulTrans. Available: https://www.simultrans.com/blog/reasons-to-translate-learningmanagement-systems.

[41] O. A. Fadil and M. Khaldi, "Learning Management Systems: Concept and Challenges," in Personalization and Collaboration in Adaptive ELearningHershey, Pennsylvania: IGI Global, 2020, pp. 158-175.

[42] N. Al-Mazrooa, Arabic Localisation: Key Case Studies for Translation Studies. Cardiff: Cardiff University, 2018.

[43] A. Omar, I. E. A. W. Shaalan, and W. I. Hamouda, "Ambiguity Resolution in Arabic Localization," (in English), Applied Linguistics Research Journal, vol. 5, no. 1, pp. 1-6, 2021.

[44] A. Omar and M. A. Alqahtani, "The implications of linguistic diversity for the ERP implementation practices in multilingual contexts," International Journal of Advanced and Applied Sciences, vol. 5, no. 7, pp. 46-52, 2018.

[45] A. Omar and A. Almaghthwi, "Towards an Integrated Model of Data Governance and Integration for the Implementation of Digital Transformation Processes in the Saudi Universities," International Journal of Advanced Computer Science and Applications, vol. 11, no. 8, pp. 588-593, 2020.

[46] J. Johnson. (2021). Distribution of internet users worldwide as of 2019, by age group. Available: https://www.statista.com/statistics/272365/agedistribution-of-internet-users-worldwide/.

[47] A. E. E. Sobaih, A. M. Hasanein, and A. E. Abu Elnasr, "Responses to COVID-19 in higher education: Social media usage for sustaining formal academic communication in developing countries," Sustainability, vol. 12, no. 16, p. 6520, 2020.

[48] R. A. Machado, P. R. F. Bonan, D. E. d. C. Perez, and H. Martelli JÚnior, "COVID-19 pandemic and the impact on dental education: discussing current and future perspectives," Brazilian oral research, vol. 34, 2020.
[49] N. Ghounane, "Moodle or Social Networks: What Alternative Refuge Is Appropriate to Algerian EFL Students to Learn during COVID-19 Pandemic," Arab World English Journal, vol. 11, no. 3, pp. 21-41, 2020.

[50] M. Lobanov and I. Hill, "Personal brand and localization management " Multilingual, vol. March, pp. 27-31, 2017.

[51] E. M. Muhiesen and M. S. Al-Ajrami, "Challenges in Translating Technical Texts," Dirasat, Human and Social Sciences, vol. 46, no. 1, pp. 322-328, 2019.

[52] A. Omar and M. Aldawsari, "Lexical Ambiguity in Arabic Information Retrieval: The Case of Six Web-Based Search Engines," International Journal of English Linguistics, vol. 10, no. 3, pp. 219-228, 2020.

[53] A. Omar and W. I. Hamouda, "The Effectiveness of Stemming in the Stylometric Authorship Attribution in Arabic," International Journal of Advanced Computer Science and Applications, vol. 11, no. 1, pp. 116$121,2020$.

[54] A. Omar and W. I. Hamouda, "Document length variation in the vector space clustering of news in arabic: A comparison of methods," International Journal of Advanced Computer Science and Applications (IJACSA), no. 2, pp. 75-80, 2020.

[55] A. Omar, B. I. Elghayesh, and M. A. M. Kassem, "Authorship attribution revisited: The problem of flash fiction a morphological-based linguistic stylometry approach," 2019.

[56] H. N. Alsager, "Towards a Stylometric Authorship Recognition Model for the Social Media Texts in Arabic," 2020.

[57] A. Lommel, A. Burchardt, and H. Uszkoreit, Multidimensional Quality Metrics (MQM) Definition. German Research Center for Artificial Intelligence (DFKI) and QTLaunchPad, 2015.

[58] A. Omar, A. F. Khafaga, and I. E.-N. A. W. Shaalan, "The Impact of Translation Software on Improving the Performance of Translation Majors."

[59] Y. A. Gomaa, R. AbuRaya, and A. Omar, "The Effects of Information Technology and E-Learning Systems on Translation Pedagogy and Productivity of EFL Learners," in 2019 International Conference on Innovation and Intelligence for Informatics, Computing, and Technologies (3ICT), 2019, pp. 1-6: IEEE. 